\title{
Flow instabilities in a vertical tube reboiler
}

\author{
M. Kessler ${ }^{1} \&$ S. Kabelac ${ }^{2}$ \\ ${ }^{1}$ Institute for Thermodynamics, Helmut Schmidt University, \\ University of the Federal Armed Forces Hamburg, Germany \\ ${ }^{2}$ Institute for Thermodynamics, Leibniz University Hanover, Germany
}

\begin{abstract}
The dynamic thermohydraulic behaviour of a vertical tube reboiler is investigated by experiments and by simulation. Natural circulation reboilers are widely used in chemical industries, especially as column evaporators. Their main components are an evaporator and a separator which are connected in a loop. The subcooled product fluid coming from the separator is heated, partially evaporated and fed back into the separator. Entering the separator the two-phase flow is separated into liquid and vapour phase due to gravity. As a result of the partial evaporation the mean density of the fluid decreases. Caused by the density difference between evaporator and separator contents, a natural circulation occurs. Under certain conditions flow instabilities will occur, triggered by different causes as for example feedback between vapour generation, flow velocity and pressure loss. To investigate these instabilities, to distinguish between them as to their type and to enable a forecast for these instabilities a technical pilot plant scale test facility is used. The main components are a vertical tube evaporator, a separator and a condenser. The evaporator is heated by steam. It is designed as a straight tube heat exchanger with seven tubes in parallel of $4 \mathrm{~m}$ length each. By varying various operating parameters such as product vapour pressure, heat load and submergence level, stable and unstable conditions can be observed and analysed. As a working fluid deionized water is used. Based on the experimental results and criteria found in literature a stability diagram is in development. Besides the ongoing experiments a computer model based on the differential volume method is in development to simulate the dynamic thermohydraulic behaviour of the system. The obtained experimental data is used to validate the model.

Keywords: flow instabilities, vertical tube reboiler, natural circulation reboiler, evaporation, stability diagram, finite volume method.
\end{abstract}




\section{Introduction}

Approximately $70 \%$ of evaporators used in chemical industry are natural circulation reboilers or thermosiphon reboilers [1]. Another example for the application of thermosyphon reboilers is their use as passive cooling devices in nuclear power plants. Their simple construction, the absence of moving parts and low operating costs are the main reasons for these applications. When used as column heater the main components are an evaporator and a separator, which are connected in a loop. Typically designed as a vertical tube heat exchanger the evaporator is normally heated by condensing steam. Coming from the separator the product liquid fluid is heated and partially evaporated in the evaporator, which results in a difference of the mean density between separator and evaporator. As a result, a self-induced, natural circulation occurs. Natural circulation systems are subject to several types of flow instabilities. The characterisation and classification of flow instabilities in natural circulation systems have been investigated in many studies, especially in the field of nuclear power technology, which are presented in the next section.

\section{Principles of flow instabilities}

Under certain conditions flow instabilities are present in natural circulation reboiler systems which cause undesirable flow oscillations. As a result difficulties occur while controlling and operating the reboiler systems. Also mechanical damages to the components caused by vibrations are reported. Due to these issues a stable operating status is of importance. Recent overviews of two-phase flow instabilities can be found in Nayak and Vijayan [2], Kakac and Bon [3] and Goswami and Paruya [4]. With respect to their mechanisms flow instabilities can be classified in two main groups, static and dynamic instabilities, which are both divided into various subgroups [5]. Static instabilities can be predicted by steady-state laws and can lead either to a different steady-state condition or to a periodic oscillating behaviour. The group of static instabilities includes for example flow excursion or Ledinegg instability, flow pattern transition instability, geysering and chugging. Dynamic instability is present when neither the cause nor the threshold of instability can be predicted from the steady-state laws as inertia and feedback effects have an important part. Dynamic instability can be divided in fundamental or pure dynamic instabilities such as acoustic oscillations and density wave oscillations and compound dynamic instabilities as thermal oscillations, boiling water reactor (BWR) instability and parallel channel instability [5]. Density wave oscillations (DWO) have been investigated experimentally and classified into two types, DWO type I and DWO type II, by Fukuda and Kobori [6]. Table 1 shows an overview of the various types of flow instabilities.

One aim of this study is to develop a stability diagram as shown in fig. 1, where the stable and unstable regions are separated by a stability boundary. The subcooling at the inlet of the evaporator or the dimensionless subcooling number vs. the heat load or the dimensionless phase change number are plotted. Both 
Table 1: Types of flow instabilities.

\begin{tabular}{ll}
\hline Static instabilities & Dynamic instabilities \\
\hline Ledinegg instability & Acoustic instability \\
Boiling crisis & Density wave oscillations (I,II) \\
Geysering & Pressure drop oscillations \\
Instability due to change in flow regime & Thermal oscillations \\
& Parallel tube instability \\
\hline
\end{tabular}

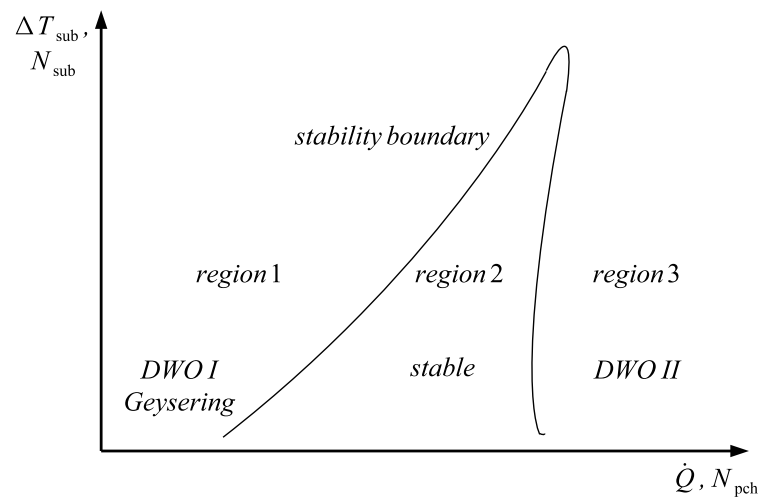

Figure 1: Typical stability map [7].

dimensionless numbers are defined in [7] as follows:

$$
\begin{gathered}
N_{\text {pch }}=\frac{\dot{Q}}{A_{\mathrm{M}} w_{\text {in }} \rho_{\mathrm{l}} \Delta h_{\mathrm{v}}} \frac{\Delta \rho}{\rho_{\mathrm{v}}} \\
N_{\mathrm{sub}}=\frac{\Delta h_{\mathrm{sub}}}{\Delta h_{\mathrm{v}}} \frac{\Delta \rho}{\rho_{\mathrm{v}}}
\end{gathered}
$$

The desired operating modus of a natural circulation reboiler is marked by region 2, where a steady circulation flow with completed boiling (in contrast to subcooled boiling) at the exit of the evaporator is present. Geysering, chugging and DWO type I can be assigned to region 1 as an unstable operating status. Region 3 is a second unstable region and mainly characterised by DWO type II. The above mentioned types of instabilities are affected by a variety of geometric and operating parameters which result in various different courses of the stability boundary curve and the characteristic of region 2. Important geometric parameters 
are the length and diameter of the evaporator tube and its surface roughness. As described below the geometry will not be changed during our experiment. As important operating parameters pressure, inlet subcooling, heating power and submergence level are identified [6]. Kumar et al. [8] have carried out various experiments investigating the stability boundaries at various pressures and inlet subcooling.

\section{Experimental setup}

The test facility which is used for the validation and development of simulation models is built in technical pilot plant scale stretching over two floors consists of three main parts: evaporator, separator and condenser. All components including the connecting pipes are made of stainless steel. To minimise heat loss all parts are insulated with mineral wool. fig. 2 shows the schematic of the test facility.

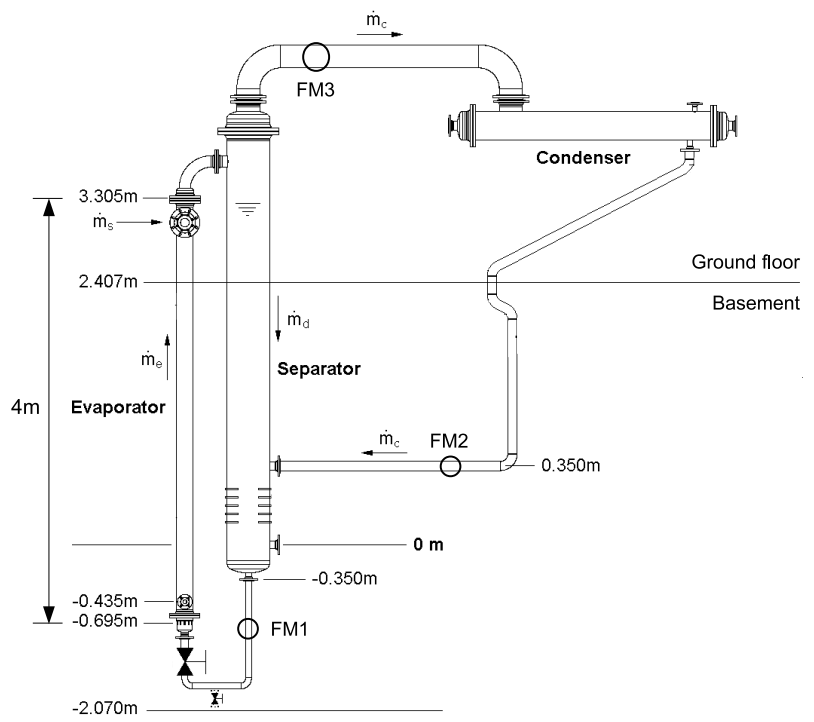

Figure 2: Schematic of the experimental setup.

The evaporator is designed as a vertical tube bundle with seven tubes of $4 \mathrm{~m}$ length each. Their outer diameter is $30 \mathrm{~mm}$ and the wall thickness is $2 \mathrm{~mm}$. fig. 3 shows a cross section of the evaporator with the adapters for pressure sensors. Superheated steam provided by a natural gas fired boiler is lead into the shell side of the evaporator and condenses at the outer surface of the tubes. Via a pneumatic valve the steam pressure can be varied and controlled. The condensed water leaving the evaporator at the lower side is conducted back to the boiler. The product fluid used here is deionized water. It comes from the separator is 


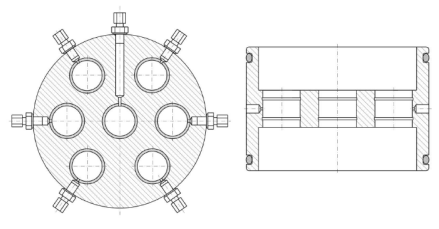

Figure 3: Cross section of the upper part of the evaporator with its seven tubes and adapters for pressure sensors.

heated and leaves the evaporator tubes in a two-phase status. The vapour phase flows to the condenser passing a demister. The separator consists of a cylindrical vessel with a volume of $0.65 \mathrm{~m}^{3}$ where the liquid phase of the product is collected. The condenser is built as a straight tube heat exchanger. The vapour phase of the product coming from the separator is condensed and flows to the lower part of the separator. Ground water fed by a cooling pond is used as cooling fluid for the condenser. During the experiment different temperatures, pressures and flow rates and the submergence level are measured. For measuring the flow rate of the overheated steam entering the evaporator and the product vapour leaving the separator ultrasonic flow meters of the type Panametrics GS 868, are applied. The flow rate of the circulating product at the lower side of the evaporator and the returning subcooled liquid product from the condenser are measured by ultrasonic flow meters of the type Panametrics UPT 868 P. The flow rate of the cooling water is measured by a turbine flow meter with an uncertainty of less than $1 \%$. The wall temperature of each evaporator tube is measured at two levels, 1 and $2 \mathrm{~m}$ below the top face of the evaporator, by 14 thermocouples soldered at the outer surface of the tubes. At the inlet and outlet of the evaporator the temperature and pressure of the product fluid is measured by thermocouples and absolute piezoresistive pressure sensors. Inlet temperature and pressure of the overheated steam are measured by a thermocouple and an absolute piezoresistive pressure sensor. Its condensate temperature is measured by a thermocouple at its outlet of the evaporator. After calibration the thermocouples have an accuracy of less than $0.1 \mathrm{~K}$. Additionally platinum resistance thermometers PT100 are used for measuring the temperatures of the product vapour leaving the separator and its condensate entering the separator, same for the inlet and outlet temperatures of the cooling water of the condenser and the inlet temperature of product fluid of the evaporator. After calibration the platinum resistance thermometers have an accuracy of less than $0.02 \mathrm{~K}$. The pressure drop across each of the seven evaporator tubes is measured by absolute piezoresistive pressure sensors at the top and bottom. A bypass level indicator, Kobold NBK-03, is used to measure and display the submergence level in the separator. All measurement outputs are sampled by a NATIONAL INSTRUMENTS data acquisition system NI cDAQ- 
9188. A continuous sampling at various sampling rates $(1-10 \mathrm{~Hz})$ ensures the exposure of the dynamic behaviour of the test loop. To indicate their influence on the thermohydraulic behaviour of natural circulation reboilers various operating parameters have been investigated. The pressure on product vapour side at the outlet of the evaporator can be varied in a range between 0.6 and 2.0 bar (abs). To investigate the influence of the driving temperature difference and the heating power the superheated steam can be conditioned in a pressure range between 1.5 bar and $7 \mathrm{bar}$, at a temperature range between $120^{\circ} \mathrm{C}$ and $190^{\circ} \mathrm{C}$. The steam mass flow rate is determined by the heat demand of the evaporation inside the evaporator tubes. As a further parameter the submergence level as a driving force can be varied between $60 \%$ and $110 \%$ of the evaporator height. To achieve reasonable results, especially in terms of heat transfer, a consistency check by using the energy balance equation for different subsystems and the overall system is carried out. In case of the evaporator the deviation of heat introduced $\dot{Q}_{\text {heat }}$ and heat absorbed $\dot{Q}_{\text {prod }}$ is less than $\pm 10 \%$ at all operating points.

\section{Experimental results}

Various operating points have been investigated. The parameters submergence level, heat load and pressure on product side have been varied as mentioned above. When reaching an operating point the parameters heat load and pressure on product side held constant. In this section a sample of experimental results is presented. First the influence of heat flux on the circulating mass flux is evaluated. The pressure on product side is held constant at these points. fig. 4 shows the circulating mass flux vs. heat flux at a submergence level of $100 \%$. As the heat flux increases the mass flux reaches a maximum and at higher heat flux the mass flux decreases due to the two-phase pressure drop. As mentioned above one aim of this study is to develop a stability diagram as shown in fig. 1. A preliminary stability diagram is presented in fig. 5, where the subcooling at the evaporator inlet as a function of heat flux is plotted at a submergence level of $100 \%$ Fig. is shown in 5 . A region with stable conditions can be allocated at moderate heat load. A condition is defined to be stable if the amplitude of the oscillations is less than $30 \%$ of the absolute value. Increasing heat load instationary conditions are entered, which is detectable by oscillations, see fig. 6 . At low heat flux oscillations can be observed, too. They show characteristics of Geysiring and can be allocated to region 1 in the stability diagram. fig. 6 shows exemplarily a stable and an oscillating operation point at same subcooling $\Delta T$ and high heat load. These points can be found on the right side of the stability diagram shown in fig. 5. To allocate these oscillations to certain regions in the stability diagram, a Discrete Fourier Transform has been performed on the data. The Discrete Fourier Transform provides for example for the oscillations shown in fig. 6 a main frequency of $f=0.3 \mathrm{~Hz}$, which equals a period of $Z=3.33 \mathrm{~s}$. The calculated period $Z_{\text {cal }}$ according to

$$
Z_{\text {cal }}=2 \cdot\left[\frac{\rho_{\mathrm{l}} \Delta h_{\mathrm{sub}}}{\dot{q}_{3}}+\frac{\Delta h_{\mathrm{v}}}{\dot{q}_{3}\left(1 / \rho_{\mathrm{v}}-1 / \rho_{\mathrm{l}}\right)} \ln \left(1+\frac{\rho_{\mathrm{v}}-\rho_{\mathrm{l}}}{\rho_{\mathrm{v}}} \dot{x}\right)\right]
$$




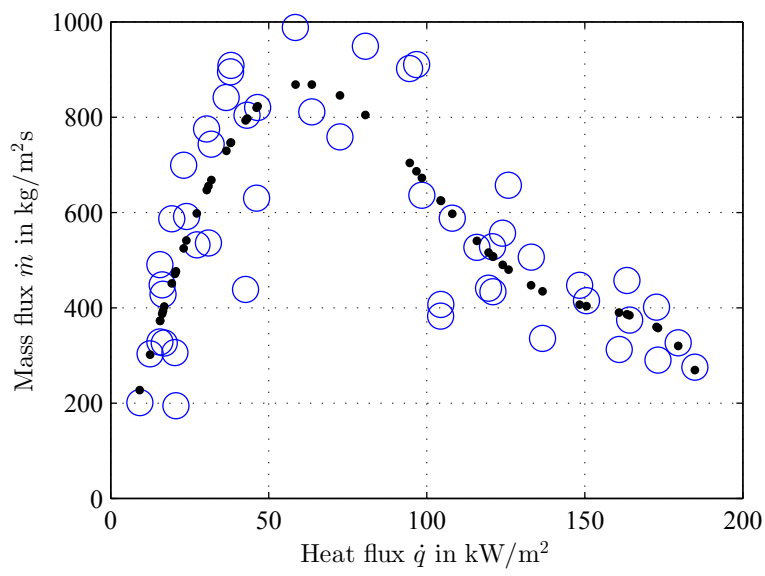

Figure 4: Circulating mass flux $\dot{m}$ vs. heat flux $\dot{q}$ at a submergence level of $100 \%$. $\bigcirc$ : data, $\bullet$ : best-fit curve.

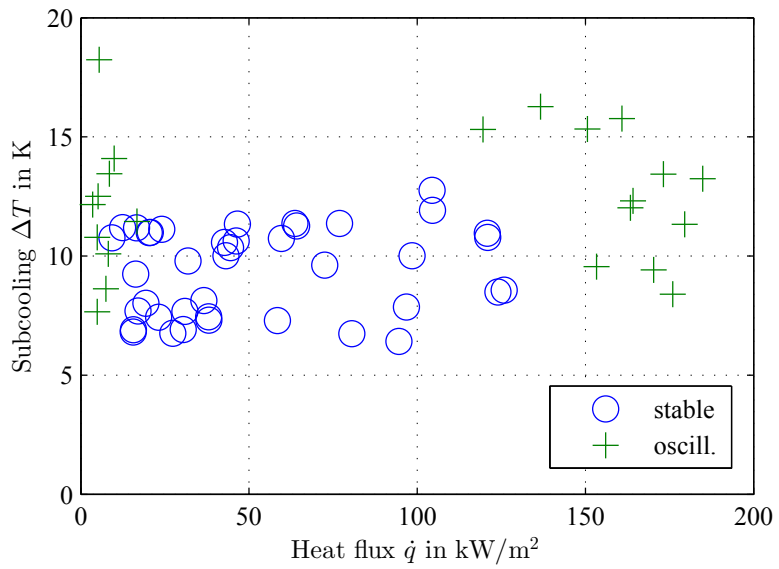

Figure 5: Preliminary stability diagram: Subcooling $\Delta T$ vs. heat flux $\dot{q}$.

taken from [7] is $Z_{\text {cal }}=3.28 \mathrm{~s}$. The equation represents two times the duration a disturbance needs to move trough the evaporator tube. Hence these oscillations can be assigned to DWO II. As shown in fig. 5 operating points with high and low subcooling are missing. They will be investigated in further experimental runs. 


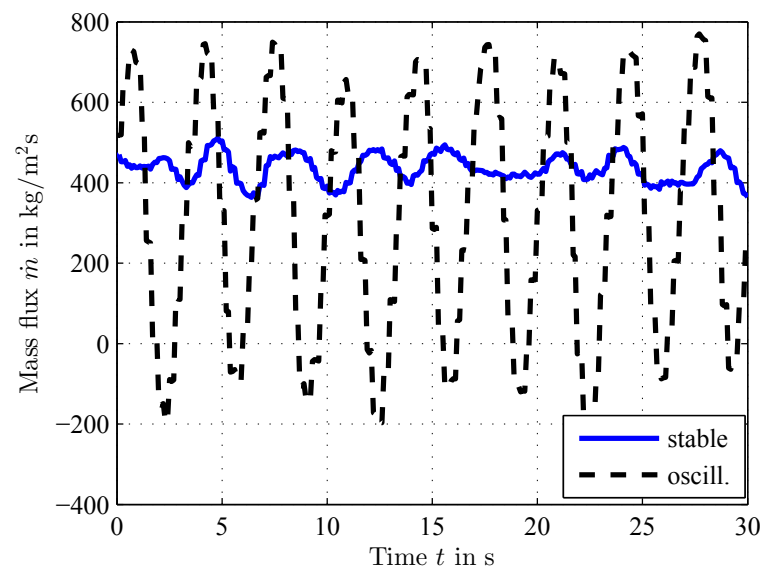

Figure 6: Mass flux $\dot{m}$ vs. time $t$. Stable and oscillating operating point at same subcooling $\Delta T=13.4 \mathrm{~K}$ at evaporator inlet.
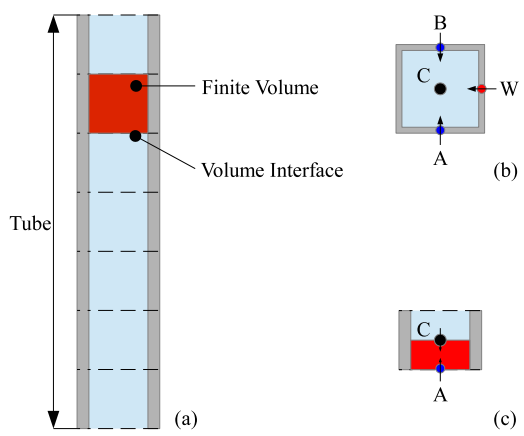

Figure 7: Finite Volume Method of the vertical tube.

\section{Model}

For setting up the dynamic physical simulation model of the natural circulation reboiler system Simscape of MATHWORKS is used. Taking the example of the vertical tube evaporator, shown in fig. $7 \mathrm{a}$, the model of the vertical tube reboiler based on the finite volume method, i.e. each component of the system is divided into control volumes. Each control volume of the component has got a set of four nodes, see fig. $7 \mathrm{~b}$. The internal node $\mathrm{C}$ provides the fluid pressure and temperature inside the control volume. Nodes A, B and W represent the interfaces with adjacent volumes. Via these so called conserving ports mass, energy and momentum can be 
exchanged between neighbouring volumes. The flow rate computations are carried out for half the control volume of the tube, shown in fig. 7c [9]. The three equations of conservation of mass, energy and momentum are implemented in the model. The correlations required for heat transfer and pressure drop calculations inside the vertical tube, in particular, of the two-phase flow are taken from Chen [10] and Friedel [11], respectively. For the heat transfer calculation the evaporation inside the vertical tube is divided into four zones: convective heating, incipience of nucleate boiling, subcooled nucleate boiling, completed boiling. The heat transfer coefficient is defined as:

$$
\alpha_{\mathrm{i}}=F_{0} \alpha_{1}+F_{1} \alpha_{\mathrm{NB}}
$$

where $\alpha_{1}$ represents the single-phase heat transfer coefficient and $\alpha_{\mathrm{NB}}$ the heat transfer coefficient due to nucleate boiling. The factors $F_{0}$ and $F_{1}$ depend on the above mentioned zones. For details, see [12]. In a first step the vertical tube evaporator has been modeled. The condensation of steam on the outer surface of the pipes is taken into account and is calculated according to [13].

\section{Conclusion}

A technical pilot plant scale test facility is used to investigate the dynamic thermohydraulic behaviour of natural circulation reboilers. Stationary and oscillating operating points has been explored. Based on the experimental data a preliminary stability diagram has been developed. Using a Discrete Fourier Transform main frequencies of the observed oscillations can be determined and hence the oscillations can be assigned to certain regions of the stability diagram. Beside the experimental investigation a model based on the finite volume method is being set up to simulate the dynamic behaviour of the system.

\section{Nomenclature}

$\begin{array}{lll}A & \mathrm{~m}^{2} & \text { area } \\ F & - & \text { factor } \\ g & \mathrm{~m} / \mathrm{s}^{2} & \text { gravity } \\ h & \mathrm{~kJ} / \mathrm{kg} & \text { specific enthalpy } \\ \Delta h_{\mathrm{v}} & \mathrm{kJ} / \mathrm{kg} & \text { vaporization enthalpy } \\ \Delta h_{\mathrm{sub}} & \mathrm{kJ} / \mathrm{kg} & \text { specific enthalpy of subcooling } \\ \dot{m} & \mathrm{~kg} /\left(\mathrm{m}^{2} \mathrm{~s}\right) & \text { mass flux } \\ N_{\mathrm{ph}} & - & \text { phase change number } \\ N_{\mathrm{sub}} & - & \text { subcooling number } \\ p & \mathrm{~Pa} & \text { pressure } \\ \dot{q} & \mathrm{~W} / \mathrm{m}^{2} & \text { heat flux } \\ \dot{q}_{3} & \mathrm{~W} / \mathrm{m}^{3} & \text { volumetric heat flux }\end{array}$




$\begin{array}{lll}\dot{Q} & \mathrm{~W} & \text { heat load } \\ \Delta T_{\text {sub }} & \mathrm{K} & \text { subcooling } \\ U & \mathrm{~m} & \text { circumference } \\ w & \mathrm{~m} / \mathrm{s} & \text { velocity } \\ z & \mathrm{~m} & \text { length } \\ Z & \mathrm{~s} & \text { period } \\ \alpha & \mathrm{W} /\left(\mathrm{m}^{2} \mathrm{~K}\right) & \text { heat transfer coefficient } \\ \rho & \mathrm{kg} / \mathrm{m}^{3} & \text { density } \\ \tau & \mathrm{N} / \mathrm{m}^{2} & \text { shear stress }\end{array}$

$\begin{array}{ll}\begin{array}{l}\text { Indices } \\ \text { heat }\end{array} & \text { heating side } \\ \text { in } & \text { inlet of evaporator tube } \\ 1 & \text { liquid } \\ \text { NB } & \text { nucleate boiling } \\ \text { prod } & \text { product side } \\ \text { v } & \text { vapour }\end{array}$

\section{References}

[1] Sloley, A.W., Avoid problems during distillation column startups. Chemical Engineering Progress, No. 7, 1996.

[2] Nayak, A. K. \& Vijayan P. K., Flow instabilities in boiling two-phase natural circulation systems: A review. Science and Technology of Nuclear Installations, ID 573192, 2008.

[3] Kakac, S. \& Bon, B., A review of two-phase flow dynamic instabilities in tube boiling systems. International Journal of Heat and Mass Transfer 51 (3-4), 399-433, 2008.

[4] Goswami, N. \& Paruya, S., Advances on the research on nonlinear phenomena in boiling. Progress Nuclear Science 53, 673-697, 2011.

[5] Boure J. A., Bergles, A. E. \& Tong, L. S., Review of two-phase flow. Nuclear Engineering and Design 25, 165-192, 1973.

[6] Fukuda, K. \& Kobori, T., Classification of two-phase flow instability by density wave oscillation model. Journal of Nuclear Science and Technology 16 (2), 95-108, 1979.

[7] Baars, A., Stationäre und instationäre Betriebszustände eines Naturumlaufverdampfers. Forts.-Ber. VDI Reihe 3 Verfahrenstechnik 779, 2003.

[8] Kumar, P., Khardekar, A., \& Iyer, K., Experimental and numerical investigation on a twophase natural circulation test facility. Heat transfer engineering 33(9), 775-785, 2012.

[9] Simscape Thermal Liquid Modeling Framework. http://www.mathworks.de. 
[10] Chen, J. C., Correlation for boiling heat transfer to saturated fluids in convective flow. I \& EC Process Design and Development 5 (3), 1966.

[11] Friedel, L., Druckabfall bei der Strömung von Gas/Dampf-FlüssigkeitsGemischen in Rohren. Chemie Ingenieur Technik 50 (3), 167-180, 1978.

[12] Dialer, K., Die Wärmeübertragung beim Naturumlaufverdampfer. PhD. Thesis ETH, Nr. 7407, 1983.

[13] Numrich, R., Müller, J., VDI-Wärmeatlas, Teil J1, 2013. 